\title{
Sexualidade e gênero: Um estudo de representações sociais com estudantes de enfermagem
}

\author{
Sexuality and gender: A study of social representations with nursing students \\ Sexualidade y género: Um estúdio de representaciones sociales com estudiantes de enfermería
}

Sabrina Emylle Torres Fernandes

ORCID: https://orcid.org/0000-0002-4703-4895

Universidade Federal de Pernambuco, Brasil

E-mail: sabrinaemylle.torres@gmail.com

Nemório Rodrigues Alves

ORCID: https://orcid.org/0000-0002-8821-872X Universidade Federal de Alagoas, Brasil

E-mail: nemorio_rodrigues@hotmail.com

Trycia Ryane de Freitas Silva

ORCID: https://orcid.org/0000-0002-9568-362X Centro Universitário Tabosa de Almeida, Brasil

E-mail: trycia_ryane@ @otmail.com

Andreza Josiany Aires de Farias

ORCID: https://orcid.org/0000-0001-6631-9186

Universidade Estadual da Paraíba, Brasil

E-mail: andrezaafarias@gmail.com

Marina Saraiva de Araújo Pessoa

ORCID: https://orcid.org/0000-0002-2125-5155

Universidade Federal da Paraíba, Brasil

E-mail: marina.saraiva@live.com

Sheila Milena Pessoa dos Santos

ORCID: https://orcid.org/0000-0001-9396-9192

Universidade Federal de Campina Grande, Brasil E-mail: sheila.milena@gmail.com

\begin{abstract}
Resumo
Objetivo: Compreender as representações de acadêmicos de Enfermagem sobre sexualidade e gênero. Metodologia: Optou-se por um estudo de natureza qualitativa, fundamentado na Teoria das Representações Sociais (RS). A população-alvo da pesquisa foi composta por estudantes do Curso de Enfermagem da Universidade Federal de Campina Grande (UFCG). Para auxílio na organização dos dados, utilizou-se o software IRaMuTeQ versão 0.7 Alpha 2. A análise fundamentou-se na análise de conteúdo. Resultados: As representações dos estudantes se mostraram diferentes em razão do período de curso, sobretudo, quando relacionadas às noções sobre o corpo e o cuidado no âmbito da Enfermagem. Emergiram três categorias analíticas: (1) Sexualidade e gênero: reconhecendo as fragilidades do processo de formação; (2) Inseguranças apontadas; (3) Necessidades de outros caminhos. Discussão: Os discursos dos estudantes revelaram uma fragilidade no processo formativo quanto à ausência de práticas e discussões que envolvessem a diversidade de gênero e a sexualidade. Conclusão: Propõe-se a implementação da temática dentro e fora das salas de aulas, permitindo ao estudante de Enfermagem refletir e vivenciar questões inerentes à sexualidade e gênero enquanto dimensões da vida humana.
\end{abstract}

Palavras-chave: Gênero; Sexualidade; Enfermagem; Representações sociais.

\begin{abstract}
Objective: To understand the representations of nursing students about sexuality and gender. Methodology: We chose a qualitative study, based on the Theory of Social Representations (RS). The target population of the research was composed by students of the Nursing Course of the Federal University of Campina Grande (UFCG). The IRaMuTeQ software version 0.7 Alpha 2 was used to aid in the organization of the data. The analysis was based on content analysis. Results: The representations of the students were different due to the period of the course, especially when related to the notions about the body and care within the scope of Nursing. Three analytical categories emerged: (1) Sexuality and gender: recognizing the weaknesses of the training process; (2) Pointed insecurities; (3) Need for other paths. Discussion: The discourses of the students revealed a fragility in the formative process regarding the absence of practices and discussions that involved the diversity of gender and sexuality. Conclusion: It is proposed to implement the theme inside and outside the classrooms, allowing the Nursing student to reflect and experience issues inherent to sexuality and gender as dimensions of human life.
\end{abstract}


Keywords: Gender; Sexuality; Nursing; Social representations.

\section{Resumen}

Objetivo: Comprender las representaciones de académicos de Enfermería sobre sexualidad y género. Metodología: Se optó por un estudio de naturaleza cualitativa, fundamentado en la Teoría de las Representaciones Sociales (RS). La población objetivo de la investigación fue compuesta por estudiantes del Curso de Enfermería de la Universidad Federal de Campina Grande (UFCG). Para ayudar en la organización de los datos, se utilizó el software IRaMuTeQ versión 0.7 Alpha 2. El análisis se basó en el análisis de contenido. Resultados: Las representaciones de los estudiantes se mostraron diferentes en razón del período de curso, sobre todo, cuando relacionadas a las nociones sobre el cuerpo y el cuidado en el ámbito de la Enfermería. Surgieron tres categorías analíticas: (1) Sexualidad y género: reconociendo las debilidades del proceso de formación; (2) Inseguridades puntiagudas; (3) Necesidad de otros caminos. Discusión: Los discursos de los discursos revelaron una fragilidad en el proceso formativo en cuanto a la ausencia de prácticas y discusiones que involucra la diversidad de género y la sexualidad. Conclusión: Se propone la implementación de la temática dentro y fuera de las aulas, permitiendo al alumnado de Enfermería reflexionar y vivenciar cuestiones inherentes a la sexualidad y género como dimensiones de la vida humana.

Palabras clave: Género; Sexualidad; Enfermería; Representaciones sociales.

\section{Introdução}

O cuidado integral deve ser entendido como uma abordagem ao indivíduo centrado em ações de saúde que considerem os sujeitos a partir de suas necessidades, sob vários olhares (Sousa \& Bernadino, 2014). Pautada na integralidade do cuidado em saúde, a abordagem da sexualidade apresenta-se como um componente essencial, na exata medida em que essa dimensão está presente ao longo da vida humana (Brasil, 2013).

A sexualidade tem sido incorporada como um fenômeno biológico, ligada ao corpo e ao desejo. Porém, a construção da sexualidade do ser humano deve ser interpretada levando-se em consideração tanto a dimensão biológica quanto social, assumindo o sujeito como um ser complexo (Miranda \& Oliveira, 2017).

A sexualidade se caracteriza como um conjunto de comportamentos conexos, os quais incluem o prazer, assim como seu revés, o desprazer, os desejos, as necessidades que a própria vida, em sua complexidade sócio-biológica, os impõem. Somente os atos e os prazeres ligados ao aparelho genital não podem por si determinar o conceito de sexualidade. A conceituação da sexualidade deve ser entendida como um conjunto de estímulos e de atividades que surgem a partir da infância, proporcionando um prazer que vai além da satisfação de uma necessidade fisiológica fundamental (Brasil, 2013). Neste sentido, de acordo com Bittencourt (2014) a revelação da sexualidade é expressa por meio do corpo, da subjetividade e da integralidade do indivíduo, abrangendo seus costumes, comportamentos e emoções, indo além do contexto biológico.

A sexualidade denominada com um fenômeno complexo e eclético, abrange os diversos aspectos culturais, históricos, biológicos e políticos, resultado de experiências vivenciadas pelo sujeito (Gesser, Oltramari \& Panisson, 2015). Nesse contexto, a saúde sexual é considerada como uma construção que se relaciona ao meio no qual o indivíduo foi socializado, perpassando toda a existência humana (Sevilla \& Orcasita, 2014).

Ao se considerar os modos como tem sido interpretada, sabe-se que a sexualidade e as relações de gênero são dois elementos que não podem ser vistos separadamente. O conceito de gênero é atribuído pelos autores Sabatel et al. (2016) como sendo qualquer construção social que se distingue entre masculino e feminino, dessa maneira, inclui-se as construções que separam corpos "femininos" de corpos "masculinos".

Ferreira (2016) afirma que a sexualidade é pensada a partir do contexto da vivência. Nela, a sexualidade encontra as questões de gênero atreladas com a temática da diferença, existindo padrões sociais que são fundamentados em estereótipos sexuais, os quais definem o ser "homem" e o ser "mulher". Nessa direção, as mulheres são ensinadas a permanecerem privadas nos ambientes domésticos e das relações pessoais, enquanto os homens se elevam no espaço público, no contexto da produção e da política. Tais estereótipos são construídos e só reafirmam o quanto a desigualdade (poder) de gênero se fortalece. 
A sexualidade articula-se com o corpo e com a perspectiva de gênero. Para Foucault (2011), o corpo é a consequência de episódios que se atravessam a partir dos valores, sentidos e discursos que definem seu funcionamento. O corpo abrange dimensões sociais, antropológicas e históricas, que juntas expressam a sexualidade e o gênero dos sujeitos. Desse modo, o autor afirma que a sexualidade é a união dos efeitos gerados nos corpos, nos comportamentos e nas relações sociais.

A sexualidade é vivenciada através da influência do meio cultural, não havendo qualquer predisposição intrínseca, biológica ou psicológica na identidade de um indivíduo que se considera heterossexual, homossexual ou bissexual. Desse modo, os sujeitos experimentam sua sexualidade a partir das suas descobertas pessoais e subjetivas (Ferreira, 2016a).

Contudo, sabe-se que a inserção da sexualidade na formação em Enfermagem tem sido incipiente ao longo do tempo. Os currículos voltados para educação sexual integral vão além de uma exposição de eventos e estratégias no quesito da promoção do sujeito sexual e do bem-estar. Devem ser focados nas experiências cotidianas dos indivíduos, aspecto fundamental para a saúde (Gubrium \& Shafer, 2014). Estudos realizados por Nogueira et al. (2017) demonstraram que acadêmicos do Curso de Enfermagem compreendiam a sexualidade enfatizando apenas a dimensão biológica, em especial o aparelho genital. Desse modo, as práticas de enfermagem, acerca da sexualidade humana, se concretizavam por meio de orientações que se distanciavam da dimensão complexa humana, abordando apenas os discursos biologicista.

Silva et al. (2019) apontam a incipiente abordagem na sexualidade durante a formação em enfermagem. Para Rocha (2016), as representações se constroem nas experiências vividas, e são resultado da interação do sujeito social com outros e com o mundo. Portanto, reconhecer as representações dos estudantes contribui para a formação de um novo saber, essencial para reformular paradigmas.

Ao considerar o estudo das Representações Sociais como um importante modo de visibilizar os modos como os sujeitos vivenciam e interpretam a sexualidade indaga-se: quais as representações sociais de estudantes de enfermagem sobre sexualidade e gênero? O presente estudo tem por objetivo compreender as representações sociais dos estudantes de enfermagem de uma instituição pública sobre sexualidade e gênero.

\section{Metodologia}

Na presente pesquisa optou-se por compreender as representações sócias dos estudantes do curso de enfermagem de uma instituição pública sobre sexualidade e gênero. Trata-se de uma pesquisa de abordagem qualitativa fundamentada na Teoria das Representações Sociais.

Moscovici (2007) afirma que as representações possuem a função de convencionalizar ser, objeto ou acontecimento, dando-lhes forma e categoria. Essas convenções permitem a classificação, reconhecimento e interpretação dos objetos, ou seja, ancoram ideias estranhas. Esse processo de ancoragem possibilita nomear os objetos, colocando-os num contexto familiar. A objetivação propõe desvendar o simbolismo da ideia e reproduzir em imagem, tornando aquilo que não é familiar, em algo reconhecido. No entanto, nem todas as palavras podem ser ligadas às imagens, seja porque não existem imagens suficientes ou, porque estão ligadas a tabus. O autor evidencia que as representações são prescritivas e que elas se impõem nas pessoas, na exata medida em que elas dão sentido às suas práticas, e estas alimentam as representações, numa retroalimentação. Para compreendê-las é necessário estudar seu ponto de origem.

A população-alvo foi composta por estudantes do curso de enfermagem da Universidade Federal de Campina Grande. O número de estudantes matriculados, considerados ativos, no curso de Enfermagem, na época do estudo era 173 e, o total de alunos inativos era 14. A amostragem do estudo utilizada na pesquisa foi a não probabilística do tipo intencional, considerouse, para tanto, o critério de saturação. Portanto, a quantidade de encontros com os grupos ocorreu de acordo com a saturação do tema, não sendo necessário o agendamento de mais momentos com os integrantes. 
Para a coleta de dados utilizou-se da técnica do Grupo focal, que se caracteriza como um procedimento que explora as interações das pessoas em determinado grupo. Ao se debater um tema ela possibilita aos integrantes exporem suas opiniões e aprofundarem a discussão. Ela envolve a conjugação de pensamentos e sentimentos permitindo, assim, ao pesquisador, uma melhor análise dos dados (Santos, Silva \& Jesus, 2016).

A coleta de dados ocorreu com a realização de três grupos focais (GF), sendo eles: GF1, GF 2 e GF 3. A quantidade de integrantes de cada GF teve uma variação de 8 a 13 pessoas, totalizando 30 estudantes. Cada grupo correspondeu a uma turma do curso de enfermagem: do $2^{\circ}$ período - (GF 1), do $6^{\circ}$ período - (GF 2) e do $9^{\circ}$ período - GF 3. Realizou-se um encontro com cada grupo.

$\mathrm{Na}$ escolha das turmas levou-se em consideração o momento do curso em que se encontraram. O GF 1 foi selecionado por se tratar de uma turma que se posiciona na fase inicial do curso. Dessa forma, com uma concepção sobre a sexualidade e gênero, pouco influenciada pelo mesmo. A turma do $6^{\circ}$ período se encontra com um pouco mais de $50 \%$ do curso realizado. A hipótese aqui é a de que o GF 2 tivesse adquirido alguma vivência sobre a sexualidade e gênero. O GF 3, no $9^{\circ}$ período foi escolhido por se encontrar na fase de conclusão do curso de enfermagem e com a possibilidade de um maior aprendizado acadêmico acerca do tema.

Utilizou-se como critérios de inclusão na pesquisa: estudantes de ambos sexos; idade superior a 18 anos; sem limitação por deficiência, religião ou renda; matriculados no $2^{\circ}$ período, $6^{\circ}$ período e $9^{\circ}$ período do curso de Enfermagem da referida universidade. Os critérios de exclusão determinados foram estudantes menores de 18 anos e alunos inativos do curso.

Para facilitar o desenvolvimento e aprofundamento da temática utilizou-se algumas estratégias, sendo elas: o uso de "frases disparadoras", exposição de imagens e apresentação de frases de apoio. Inicialmente, a utilização de "frases disparadoras" relacionadas à sexualidade fomentaram a discussão e reflexão sobre o tema.

Com relação as imagens como utensílio metodológico, utilizou-se imagens que representavam os diversos aspectos de sexualidade e gênero com objetivo de promover a discussão. Dessa forma, Oliveira et al. (2016) concluíram que as diferentes possibilidades de uso da imagem como instrumento metodológico reproduz sua importância no campo da pesquisa qualitativa.

As imagens foram extraídas aleatoriamente do Google Imagens. Elas tiveram como descritores: "sexualidade"; "sexualidade na infância"; "sexualidade na adolescência"; "sexualidade na pessoa adulta"; "sexualidade na terceira idade"; "sexualidade e enfermagem"; "sexualidade e saúde"; "sexualidade e deficiência"; "sexualidade e diversidade sexual e de gênero"; "sexualidade e tabu"; "procedimentos cirúrgicos e sexualidade" e "ostomia e sexualidade". Os integrantes dos Grupos Focais (GFs) tiveram acesso a 50 imagens.

A partir de estudos realizados por Ressel (2008), elaborou-se frases de apoio sobre concepções acerca da sexualidade com o objetivo de estimular a discussão. Essas frases foram ditas pelo moderador nas discussões, mediante a necessidade de mais interação pelo Grupo Focal.

Para auxilio no manejo das entrevistas, realizou-se um planejamento com a ajuda de um roteiro feito pelos pesquisadores. Enviou-se um convite eletrônico prévio aos participantes da pesquisa contendo nele o cronograma da reunião. Nele havia a data, a hora, o credenciamento, o momento do lanche e do encerramento. Apesar dos esforços, alguns alunos não compareceram.

Realizou-se a coleta de dados em uma sala de aula da referida universidade nos dias 17 e 18 de agosto de 2017. Essa sala de aula dispõe de recursos como: tapete do tipo tatame, ventilação instrumental, iluminação, aparelho de som, cadeiras e almofadas. Disponibilizou-se lanches para os participantes com o objetivo de tornar a reunião mais agradável. Tais características tornaram este local acolhedor e tranquilo.

Com fulcro nas evidências levantadas na pesquisa, os encontros foram realizados a partir de três fases. Primeiramente, com o uso das "frases disparadoras" sobre a sexualidade e gênero. Em seguida, com a exposição das imagens para os 
participantes e, por fim, com a apresentação das frases de apoio, momento no qual foi solicitado aos participantes que externalizassem sua compreensão sobre o que foi lido e justificassem sua resposta.

Após a exposição das frases e imagens solicitou-se aos participantes que comentassem suas impressões e percepções sobre o tema para que, a partir daí a discussão desse início. Durante o encontro utilizou-se um gravador para o arquivamento da discussão, bem como, um diário de campo, o qual teve a função de armazenar anotações e impressões acerca de cada grupo focal.

Concomitante a coleta de dados, realizou-se a análise de conteúdo. Essa técnica de análise é realizada a partir de uma avaliação do texto das entrevistas ou observada pelo pesquisador (Silva \& Fossá, 2015). De acordo com Carlomagno e Rocha (2016) a análise de conteúdo é composta pela fase de planejamento, coleta e sistematização dos dados. Dessa forma, possibilita a classificação e categorização de qualquer tipo de conteúdo.

Nesse estudo, foram desenvolvidas as seguintes etapas: audição e transcrição das entrevistas coletadas; leitura e classificação dos resultados obtidos; organização do corpus textual no software Interface de $R$ pour les Analyses Multidimensionnelles de Textes et de Questionnaires (IRaMuTeQ) versão 0.7 Alpha 2 e construção teórica voltada à sexualidade e gênero, no tocante às contribuições para a sua formação acadêmica.

Construiu-se uma figura com base na ligação das palavras, a partir de uma ferramenta do software IRaMuTeQ denominada de Análise de Similitude, ferramenta através da qual as figuras puderam ser interpretadas. Apesar de algumas falas exigirem a necessidade de adequação à norma padrão da gramática, na interpretação o sentido das falas dos estudantes não foi alterado.

Com relação aos aspectos éticos, esta pesquisa atende às normas da pesquisa com seres humanos, emanadas pela Resolução 466/12 e Norma operacional 001/2013, ambas do Conselho Nacional de Saúde (CNS). Neste sentido os participantes assinaram o Termo de Consentimento Livre e Esclarecido (TCLE). Sobre isto, salienta-se que a presente pesquisa foi aprovada no Comitê de Ética do Hospital Universitário Alcides Carneiro (HUAC) com o parecer No 2.163 .408 e do Certificado de Apresentação para Apreciação Ética $(C A A E)$ Nº $^{\circ}$ 69371317.2.0000.5182 em 07 de julho de 2017.

\section{Resultados}

\section{Caracterização dos participantes}

Participaram da pesquisa trinta estudantes $(n=30)$. A maioria dos participantes era do sexo feminino $(n=24)$, com idade entre 18 e 26 anos, predominando aqueles entre 18 e 21 anos $(n=17)$. A religião referida predominante foi a católica $(n=21)$, seguido por protestantismo $(n=07)$ e dois informaram não possuir religião $(n=2)$. A maioria $(n=17)$ informou não possuir parceria sexual no momento da pesquisa.

Ao interpretar as narrativas dos estudantes observou-se não haver disparidade nas respostas relacionadas a sexo, idade, orientação religiosa e parceria sexual. Contudo, as representações sociais se mostraram diferentes em razão do período de curso, sobretudo quando relacionadas ao cuidado em Enfermagem.

A Figura 1 é um dos resultados da análise que culminou na divisão em três categorias analíticas, quais sejam: (1) sexualidade e gênero: reconhecendo as fragilidades do processo de formação; (2) inseguranças apontadas; (3) necessidades de outros caminhos. 
Figura 1 - Análise de similitude dos discursos. Campina Grande, Paraíba, 2018.

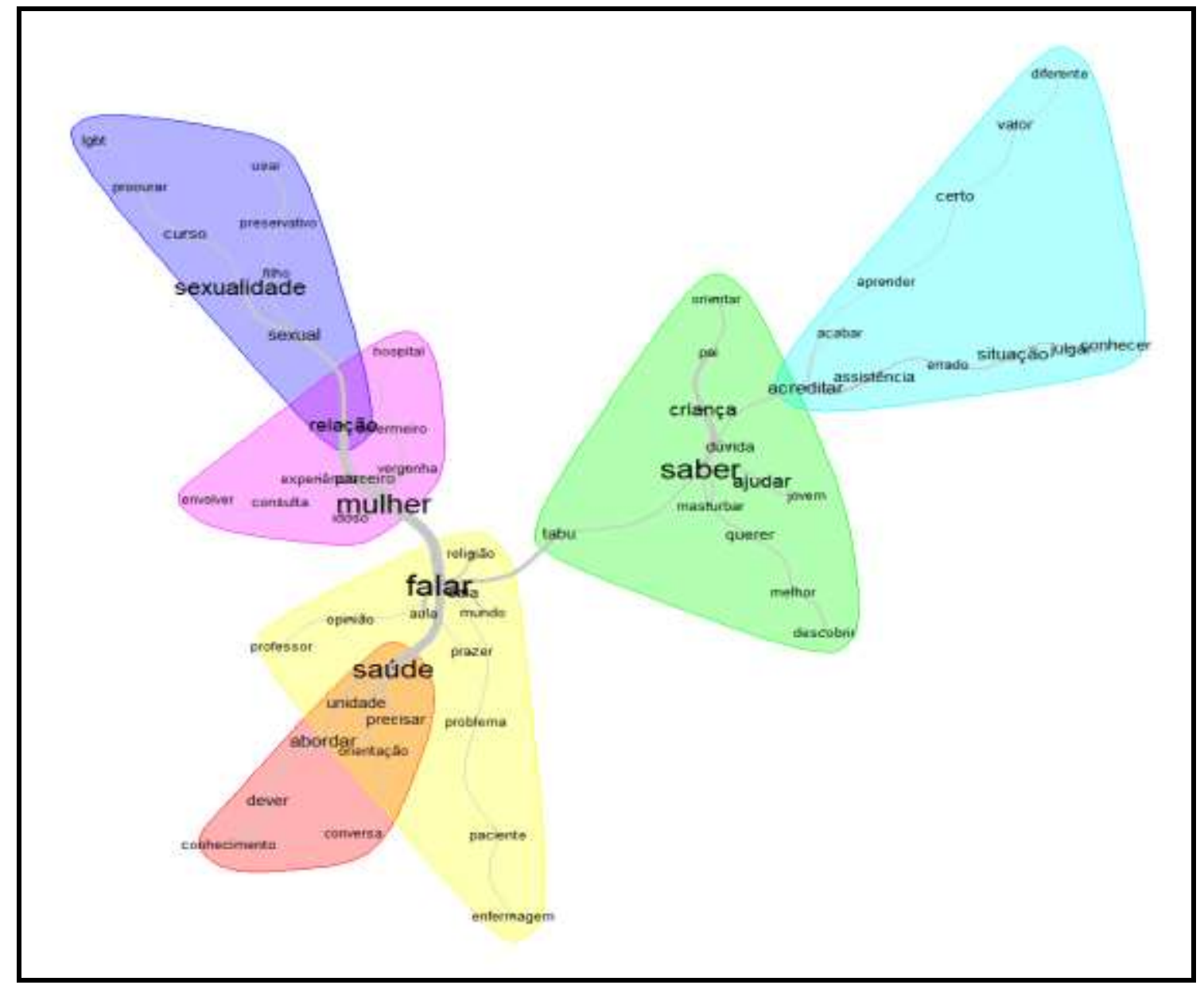

Fonte: Autores da pesquisa. Organizado com base no software IRAMUTEQ 0.7 Alpha.

\section{Categoria analítica 1- Sexualidade e gênero: reconhecendo as fragilidades do processo de formação}

Após a análise da primeira categoria compreendeu-se as representações sociais dos estudantes do Curso de Enfermagem da UFCG sobre sexualidade e gênero nas práticas acadêmicas, dentro e fora das salas, no que tange à sua formação. Evidenciou-se nos discursos emitidos a presença de dificuldades na assistência aos indivíduos frente à perspectiva da sexualidade e gênero. Neste sentido, percebeu-se algumas inquietações dos estudantes ao tratarem da responsabilidade na abordagem aos pacientes como futuros Enfermeiros.

As palavras "saúde", "orientação" e "conversa" mostraram-se interligadas na figura. Dessa forma, compreende-se que é patente a preocupação de uma orientação benéfica para o paciente, sobretudo na comunicação. As falas mostram que os participantes reconhecem a importância do diálogo sobre sexualidade. Contudo, não se implicam nesse processo.

Eu acredito que se uma pessoa chega com dúvidas no hospital sobre sua sexualidade é uma inquietação que ele está tendo com ele. Então, eu acredito que como Enfermeiro eu não sei se iria. Eu não diria, é isso, é isso. Eu ia dizer para ele tentar se descobrir porque é uma coisa natural, essa dúvida dele iria acabar sendo cessada. Que ele tivesse paciência porque não é um bicho de sete cabeças, né? (GF 1)

Essa imagem aqui são duas crianças, isso remete ao fato de a sexualidade voltada ao próprio ato sexual ser descoberto cada vez mais cedo e infelizmente ainda existem pais que não orientam seus filhos porque acham que se 
orientar está incentivando o filho. Então, é importante tanto os pais orientarem, se eles não se sentirem à vontade procurar o próprio serviço de saúde para as crianças e jovens serem orientados. Porque é melhor aprender com a família ou com profissionais do que descobrirem pelo mundo que não ensina da maneira certa e eles virem a se prejudicar futuramente. (GF 3)

Os vocábulos "sexualidade", "curso", "LGBT" (Lésbicas, Gays, Bissexuais, Travestis, Transexuais e Transgêneros) e "sexual" são palavras que estão interligadas na figura. Sendo assim, os entrevistados relacionaram suas experiências relacionado à temática sexualidade e gênero dentro do ambiente acadêmico.

Durante o curso há pouca aproximação com a temática da sexualidade e diversidade sexual. Quando questionados acerca das vivências durante a graduação, os acadêmicos do GF 1 comentaram a experiência de aceitação ao lidar com a sexualidade de colegas de turma, assim como, foi relatado o único contato com o tema em um seminário sobre a população LGBT. Suas falas direcionam a expectativa de terem mais contato com a temática sexualidade e gênero. Essas representações sociais enfatizaram o surgimento de mais discussões referentes ao tema abordado.

Há a experiência de colegas de sala que são bissexuais e homossexuais, mas eles se demonstraram naturalmente. Eles mesmo falaram: 'sou homossexual, sou bissexual.' E a gente aceitou de boa. E eles tinham medo de que a gente não aceitasse eles pela escolha deles. (GF 1)

A gente fez um trabalho sobre LGBT. (GF 1)

Acho que durante a graduação a gente vai ter uma experiência maior e quando a gente for atuar acho que a gente vai conseguir atuar. (GF 1)

Ainda acerca da aproximação do tema da sexualidade e gênero durante a graduação, os estudantes do GF 2 e GF 3 referiram ter o contato com o tema nos componentes curriculares Saúde Coletiva, Saúde da Mulher e Sociologia e Antropologia. Porém, segundo eles, foram abordadas de modo superficial, não enfatizando a assistência de Enfermagem para a diversidade de gênero.

Eu acho que o único momento em que foi falado assim diretamente sobre isso foi em Saúde Coletiva que foi um seminário, mas fora isso nada. Foi sobre LGBT, mas depois disso nada foi falado. (GF 2)

Falou em Saúde Da Mulher, não é? Das relações de homem com homem, mas também não foi muito profundo, foi bem superficial. (GF 2)

Vimos sobre sexualidade em Sociologia e Antropologia também, a gente fez algumas reflexões, mas nada que nos oriente de fato pra intervenções de enfermagem dentro dessa temática. Acho que faltou muito a questão da intervenção de Enfermagem para esses casos que podem surgir, que a gente também tem que ter esse olhar mais aberto, quando a gente encontra com os pacientes, com os usuários, para ter essa visão também de sexualidade. (GF 3)

\section{Categoria analítica 2- Inseguranças apontadas}

As palavras "saúde", "falar", "problema", "enfermagem" e "paciente" estão entrelaçados na figura, remetendo às dificuldades na prática de Enfermagem ao se tratar da sexualidade e gênero, no contexto da área de Saúde. Sendo assim, outro 
ponto discutido pelos estudantes foi a assistência nos estágios em conjunto com os profissionais enfermeiros atuantes. Nestes estágios foram relatados a resistência dos enfermeiros ao tratar a sexualidade e gênero do paciente. Foram proferidos discursos de falta de acolhimento dos pacientes, de haver julgamentos acerca da vida sexual do paciente e ausência de diálogo durante o atendimento aos mesmos. Nesta direção:

Isso aconteceu comigo. Eu fui perguntar por uma amiga minha que estava com vergonha. Então a enfermeira olhou para a minha cara e fez: 'Mulher, fizesse sem proteção, foi? Tanta camisinha aí sendo distribuída, como é que você faz sem proteção?' Ai eu falei: 'Não. Não é para mim não'. (GF 2)

A gente estava na consulta de planejamento familiar, eu e a Enfermeira, e aí na leitura de exames também e chegou uma mulher, já aos quarenta anos, mas saiu, a gente fez a consulta, chegou outra depois, então a enfermeira depois disse: 'Ainda bem que você não perguntou sobre a sexualidade dela porque as duas são casadas'. Já criou uma barreira. (GF 3)

Teve uma situação em que a mulher viu o lubrificante e perguntou o que era. Não sabia o que era. E responderam que era um lubrificante. E a mulher perguntou se serve para trás também. E um profissional que estava lá ficou bem envergonhado e saiu da sala. Ou seja, o próprio profissional da área de saúde tem vergonha de falar sobre qualquer coisa em relação a sexualidade ou ao sexo. (GF 3)

A aproximação das palavras "falar", "enfermeiro" e "vergonha" evidencia-se na figura. Nesse sentido, os sentimentos de: receio, vergonha e timidez foram desvelados pelos estudantes ao se tratar no atendimento voltado aos questionamentos da sexualidade dos pacientes. Foi relatado a dificuldade no manejo da conversa com pacientes mulheres, onde os estudantes enfatizaram o constrangimento envolvido ao se tratar da associação da sexualidade e gênero. Nesse contexto, evidenciou-se a inibição do estudante quando questionado sobre a quantidade de parcerias sexuais da paciente durante o atendimento.

Na questão de abordar eu mesmo ficaria receosa, eu não ia saber o que falar na verdade. Se fosse uma pessoa que chegasse, você percebendo que ela era colaborativa com a gente, então, assim, teria um começo de uma conversa. Mas se fosse uma pessoa muito retraída, eu não ia saber como fazer as perguntas. (GF 1)

Em um atendimento teve uma mulher que falou que havia tido mais de vinte parceiros, menina eu fiquei morta, fiquei com vergonha. (GF 2)

\section{Categoria analítica 3- Necessidades de outros caminhos}

Os termos: "saúde", "orientação", "conhecimento" e "precisar" são observados na figura. A solução para mudança no âmbito assistencial da saúde voltada à sexualidade e gênero na vida profissional do Enfermeiro foi citado pelos estudantes. Sendo proposto por eles a procura de capacitação e atualizações no curriculum, possibilitando mais conhecimento para facilitar o manejo na assistência da sexualidade e gênero voltados ao paciente.

Se capacitar mais, procurar mais sobre isso. É porque tem tantos cursos por aí, UNASUS liberando vários, aquele de LGBT tem lá bem interessante. E acho que toda a oportunidade que a gente tiver de aprender mais para nós mesmo, é interessante como profissional de saúde, a gente precisa se reinventar a todo momento, cada um é diferente do 
outro e a gente precisa suprir a necessidade daquela pessoa. Então se eu só tiver meu conceito e parar no tempo e espaço eu não vou proporcionar isso para ninguém. (GF 2)

Eu acho assim, que para a gente que está quase terminando o curso, eu acho que vai depender mais da gente procurar, ir atrás, se informar. Se eu não me engano tem curso no UNASUS que ele oferta a questão da sexualidade. Então eu acho que assim, depende mais da gente, a gente se preparar para receber esse tipo de usuário na unidade ou em qualquer outro local, qualquer outra complexidade. (GF 3)

Na figura observou-se a aproximação dos termos: "falar", "saúde", "professor" e "abordar". A articulação dessas palavras direciona a crítica na fala de um acadêmico do GF 3 acerca do modelo de assistência biomédico que é repercutido dentro da Universidade. Em uma das falas, o estudante refere à ausência de um cuidado integral ao paciente, incluindo o distanciamento de aspectos inerentes à sexualidade e gênero.

Mas eu acho que, assim, o problema de tudo isso tá muito no fato de, a gente sai da Universidade, a gente vê o paciente, aí hoje é dia de hipertenso e quando chega na unidade e vai verificar pressão, com diabético glicemia, vai passar na consulta, vai precisar renovar a prescrição, você simplesmente volta pra hipertensão somente pra patologia que ele tem, todos os outros fatores que envolvem a vida desse sujeito, você descaracteriza ele como pessoa, que vive, que tem desejos, que tem prazeres, a gente esquece disso nas consultas. A gente esquece porque isso não é enfatizado durante a graduação, durante a nossa formação. (GF 3)

Por outro lado, a disciplina de Saúde da Mulher trouxe uma contribuição importante para os acadêmicos de enfermagem. Nota-se na fala de um dos estudantes abaixo que apesar da temática de sexualidade e gênero ser um tabu social, o componente curricular referido possibilita orientações adequadas para um cuidado integral a mulher, incluindo benefícios no tocante à masturbação feminina.

Eu acho um tabu social ainda. Eu vou falar a minha opinião, ao meu ver, a única pessoa que eu vejo, que mandaria a mulher que estava sem libido se masturbar era uma das professoras de [componente curricular] Saúde da Mulher. (GF 3)

\section{Discussão}

Diante dos discursos dos participantes compreendeu-se que as questões referentes à diversidade de gênero ainda são pouco discutidas- Nesse sentido, os autores Madureira e Branco (2015) afirmam que a temática do respeito à diversidade de gênero tem sido complexa, envolvendo pontos polêmicos, preconceitos seculares e que são afetivamente enraizados.

De acordo com Conceição (2017) a perspectiva de gênero se encontra articulado nos símbolos, representações culturais, nas normas, doutrinas, nas instituições e organizações sociais, assim como, nas identidades subjetivas. Tais componentes funcionam como constituintes pelo qual o poder do sexo masculino prevalece face ao sexo feminino. Desse modo, a repressão feminina fica evidente nas relações de poder que se sobressaem dentro do âmbito social.

As relações de gênero permeadas pelo machismo e pelo sexismo construídas historicamente na sociedade se tornam responsáveis pelos papéis sociais destinados a homens e mulheres (Silva \& Mendes, 2015). Nesse sentido, apesar dos avanços acerca do papel da mulher na sociedade, é notória a sua privação, incluindo aspectos relacionados ao tabu nas questões sexuais 
voltados ao corpo feminino. Nascimento et al. (2020) apontaram que em seu estudo com adolescentes e jovens, o diálogo sobre temática relacionada a sexualidade era permeado por dúvidas, medos e constrangimentos.

Na saúde, a abordagem da sexualidade e gênero relaciona-se a busca por uma atenção integral e de qualidade, mas que por outro lado encontra, desde a formação, inúmeras barreiras para sua efetiva sua inserção. Sabe-se que a formação tem inserido a abordagem da sexualidade de forma pontual e ainda sob o ponto de vista biológico (Kloh, et al., 2014). Especificamente na enfermagem, a temática da sexualidade e gênero é retratada por atitudes evasivas de esquiva, negação, hesitação, silêncios e fuga do assunto pelo profissional, sobretudo quando os pacientes apresentam demandas sobre esse tema (Junqueira, 2013).

A existência de uma estrutura heteronormativa é responsável pela reprodução de discursos e sentidos que interferem no comportamento dos indivíduos e do coletivo (Schultz \& Barros, 2014). Nesta direção, a relação entre questões voltadas ao gênero e diversidade sexual estão entrelaçadas e foram discutidas entre os participantes, enfatizando o preconceito sociocultural existente voltado à diversidade sexual.

Em relação a orientação sexual nos serviços de saúde, a maioria dos participantes expressaram sentimentos de despreparo ao lidar com a sexualidade e gênero do paciente, assim como, quando submetidos a situações de atendimento, durante a consulta, demonstraram insegurança e vergonha.

De acordo com Campos (2015) práticas que deixam de abordar a sexualidade em sua dimensão histórico-social (re)produzem preconceitos, discriminação, marginalização e exclusão dos sujeitos envolvidos. O mesmo autor ainda afirma que tais práticas podem advir por fatores associados a política, economia, religião, entre outros. No tocante à religiosidade, Cortes et al. (2021) afirmam que a religião tem um papel importante na vida das pessoas que a praticam inclusive na vivência da sexualidade. Diante disso, os participantes tomaram a fala de que é existente dentro da nossa sociedade uma negligência dos profissionais atuantes nos serviços de saúde frente às perspectivas de sexualidade e gênero.

No que diz respeito às dificuldades na abordagem da sexualidade e gênero, os acadêmicos participantes da pesquisa ressaltaram a falta de preparo durante a graduação. Também foi relatado a configuração de um atendimento voltado ao modelo biomédico, no qual apenas a doença é enfatizada, negligenciando-se uma assistência configurada nos aspectos biopsicossocial do sujeito. Apesar dos participantes enfatizarem as dificuldades durante a graduação, os mesmos referiram que deve ser realizado um atendimento ao paciente de uma maneira abrangente, em que se ressalta a importância de resolver as dúvidas e questionamentos do indivíduo.

O empoderamento feminino também foi outro ponto refletido pelos acadêmicos. Eles revelaram em seus discursos a importância do componente curricular Saúde da Mulher na formação dos mesmos. Desse modo, evidencia-se um ponto positivo na abordagem da temática sexualidade e gênero direcionados à saúde feminina.

\section{Conclusão}

As representações sociais dos estudantes de todos os Grupos Focais relacionadas à temática da sexualidade e gênero foram vistas sob um olhar isolado dos componentes biológicos, sociais e psicológicos. Nesse sentido, expressou-se nos discursos as fragilidades do processo formativo do curso de enfermagem, deixando de lado uma abordagem integral aos sujeitos.

As práticas e experiências durante a graduação revelaram-se ausentes em discussões que tivessem como foco a assistência de Enfermagem na perspectiva da diversidade de gênero e sexualidade. Dessa forma, propõe-se a implementação da temática dentro e fora das salas de aulas, permitindo ao aluno vivenciar questões inerentes à vida humana, incluindo assim, a sexualidade e gênero. Respeitando a multidimensionalidade do ser humano biopsicossocial. 
Esta pesquisa tem como contribuição uma reflexão crítica das representações dos acadêmicos de Enfermagem no âmbito da sexualidade e gênero, facilitando a identificação de estratégias e discussões para a formação dos estudantes de Enfermagem. Evidenciou-se a dificuldade na categorização dos resultados, no qual as falas dos estudantes abordaram diversos posicionamentos dentro dos discursos dentro de um mesmo tema. Salienta-se que não é intuito dessa pesquisa esgotar o tema. Nesse sentido, foram feitas escolhas para simplificar a organização do presente estudo. Portanto, propõe-se a produção de novos estudos que abordem a temática referida.

Destaca-se que as representações dos estudantes acerca da baixa inserção da temática da sexualidade e gênero converge com o fato dos estudantes de Enfermagem necessitarem de maior instrumentalização para o cuidado, marco do cuidado biomédico. Esse aspecto revela que a dificuldade do estudante em abordar a sexualidade imbrica-se por um lado na incipiente inserção durante a formação, por outro lado, desvela a necessidade intrínseca do Enfermeiro de normatização da assistência. Contudo, o cuidado e a abordagem da sexualidade e gênero requerem do acadêmico e do enfermeiro uma postura ativa no cuidado, onde a disposição para abordagem dessa temática é fundamental.

Como propostas de enfrentamento dos tabus e preconceitos presentes no contexto da formação, sugere-se a produção de debates em que coloquem em foco a importância da integralidade do cuidado a todos os seres humanos, considerando-os como seres sociais complexos. Deve-se levar em consideração questões fundamentais, como o incentivo ao empoderamento feminino e a abordagem integral do ser humano no campo da diversidade de gênero. Nesse sentido, o gênero deve ser entendido como um conjunto de relações, atribuições e experiências que possibilitam a apropriação de uma consciência social da sua dimensão biológica/individual.

\section{Referências}

Bittencourt, R. M. R. (2014). Relações de gênero e sexualidade na infância: a escola como espaço de (des)construção das diferenças. Roteiro, 1 (1), $145-164$.

Brasil (2013). Saúde sexual e saúde reprodutiva. Ministério da Saúde.

Campos, L. M. L. (2015). Gênero e diversidade sexual na escola: a urgência da reconstrução de sentidos e de práticas. Ciênc. educ. (Bauru), 21 (4), 1-4.

Carlomagno, M. C., \& Rocha, L. C. (2016). Como criar e classificar categorias para fazer análise de conteúdo: uma questão metodológica. Revista Eletrônica de Ciência Política, 7 (1), 173-188.

Conceição, A. C. L. (2017). Teorias feministas: da “questão da mulher” ao enfoque de gênero. Revista Brasileira de Sociologia da Emoção, 8 (24), $738-757$.

Cortes, H. M. et al. (2021). Sexualidade e Religiosidade: uma revisão integrativa de literatura. Reseach, Society and Development, 10 (2), 1-11.

Ferreira, M. P. (2016). Currículo, gênero e sexualidade: questões indispensáveis à formação docente. Revista Margens Interdisciplinar, 9 (12), $37-56$.

Foucault, M. (2011). Sexualidade, corpo e direito. Cultura Acadêmica.

Gesser, M., Oltramari, L. C., \& Panisson, G. (2015). Docência e Concepções de Sexualidade na Educação Básica. Psicol. Soc., 27 (3), 558-568.

Gubrium, A. C. \& Shafer, M. B. (2014). Sensual sexuality education with young parenting women. Health Education Research, 29 (4), 649-661.

Junqueira, L. C. U. et al. (2013). Análise da comunicação acerca da sexualidade, estabelecida pelas enfermeiras, com pacientes no contexto assistencial do câncer de mama. Interface. 17 (44), 89-101.

Kloh, D. et al. (2014). Princípio da integralidade do cuidado nos projetos político-pedagógicos dos cursos de Enfermagem. Revista Latino-Americana de Enfermagem, 22 (4), 693-700.

Madureira, A. F. A. \& Branco, A. U. (2015). Gênero, sexualidade e diversidade na escola a partir da perspectiva de professore s/as. Temas em Psicologia, 23 (3), 577-591.

Miranda, C. S. \& Oliveira, G. F. (2017). Problematizar o tema sexualidade no contexto escolar: reflexões sobre as lacunas da formação dos professores de ciências. Anais do XI Encontro Nacional de Pesquisa em Educação em Ciências -Santa Catarina, Florianópolis, 1-10.

Moscovici, S. (2007). Representações Sociais Investigações em Psicologia Social. Vozes.

Nascimento, M. A. A. et al. (2020). Eu falo, tu falas e ninguém ouve: conversas sobre sexo e sexualidade entre adolescentes e jovens no espaço escolar. Reseach, Society and Development, 9 (8), 1-17.

Nogueira, I. S. et al (2017). Pesquisa-ação sobre sexualidade humana: uma abordagem Freiriana em enfermagem. Cogitare Enfermagem, 22 (1), 1-10. 
Research, Society and Development, v. 10, n. 5, e28810515035, 2021

(CC BY 4.0) | ISSN 2525-3409 | DOI: http://dx.doi.org/10.33448/rsd-v10i5.15035

Oliveira, A. et al. (2016). A iconografia na pesquisa psicossocial. CIAIQ 2016, 2 (1), 99-108.

Ressel, L. B. et al. (2008). O uso do grupo focal em pesquisa qualitativa. Texto contexto - enferm, 17 (4), $779-786$.

Rocha, R. F. (2016). Representações Sociais da Saúde Mental. Revista Eletrônica Científica Inovação e Tecnologia, 2 (14), 95-113.

Sabatel, G. M. G., et al. (2016). Gênero e Sexualidade na Educação Física Escolar: Um Balanço da produção de artigos científicos no período entre 20042014 nas Bases do Lilacs e Scielo. Pensar a Prática, 19 (1), 196-208.

Santos, R. C. S., Silva, A. C. T., \& Jesus, M. P. (2016). Grupo Focal como Técnica de Coleta De Dados na Pesquisa em Educação: Aspectos Éticos e Epistemológicos. Encontro Internacional de Formação de Professores e Fórum Permanente de Inovação Educacional, 9 (1), 1-13.

Schultz, L. \& Barros, P. M. (2014). O lampião da esquina: discussões de gênero e sexualidade no Brasil no final da década de 1970. Revista de Estudos da Comunicação, 15 (36), 1-15.

Sevilla, T. M. \& Orcasita, L. T. (2014). "Hablando de sexualidad": una mirada de los padres y las madres a los procesos de formación con sus hijos/as adolescentes en estratos populares de Cali. Av.enferm., 32 (2), 191-205.

Silva, T. R. F. et al. (2019). Representações dos estudantes de enfermagem sobre sexualidade: entre estereótipos e tabus. Trabalho, Educação e Saúde, 17 (2), e0020233.

Silva, A. H. \& Fossá, M. I. T. (2015). Análise de conteúdo: exemplo de aplicação da técnica para análise de dados qualitativos. Dados em Big Data, 1 (1), 2342 .

Silva, M. C. \& Mendes, O. M. (2015). As marcas do machismo no cotidiano escolar. Caderno Espaço Feminino, 28 (1), $90-99$.

Sousa, S. M. \& Bernardino, E. (2014). Gerenciamento de enfermagem para o cuidado integral: revisão integrativa. Revista de enfermagem UFPE online, 9 (6), 8312-8321. 